\title{
Carry Trades and Tail Risk of Exchange Rates
}

\author{
Chanaka N. Ganepola ${ }^{1}$
}

\begin{abstract}
Historically, Carry trades have been a success story for most investors and a major source of funds for emerging economies maintaining higher interest rates. Therefore it is a timely topic to investigate the risk embedded in such transactions and to what extent the carry trade returns explain the tail risk. Initially, this research estimates the tail index of all the currencies and formulates a unique inverse function for all the currencies in relation to Power laws, with the idea of estimating the respective Value-at-Risk. This research considers twenty five currencies and replicates them in to five portfolios based on the annualised daily return of a weekly forward contract. Trade was executed assuming a U.S. investor, who goes long in the high return portfolio and short in the low return portfolio. Further, this research examines the impact of carry trade returns on the overall tail risk within the context of foreign exchange and interest rate gain in long and short positions of the trade. The results indicate that tail risk cannot be explained effectively by its returns because of its exponential nature. However, this paper finds that, the tail risk is mostly influenced by the long position of the carry trade. Furthermore, the return of the foreign exchange component appears to have a better explanation on the tail risk compared to the interest rate return. The Value-at-Risk analysis also suggests that the tail risk of overall strategy is influenced by the tail risk of foreign exchange component embedded in the long position of the trade.
\end{abstract}

Key Words: Heavy-tailedness, Carry Trade, Value-at-Risk

JEL Classification: F30, F37, G15

1 I sincerely thank Dr. Pasquale Della Corte and Mr. Xi Chen of Imperial College, London, and Dr. Sumila Wanaguru of the Central Bank of Sri Lanka for their valuable guidance and feedback. The author is also thankful to anonymous reviewers. cnganepola@gmail.com 


\section{Introduction}

Carry trade strategy is a popular investment strategy when it comes to Foreign Exchange trading. According to Uncovered Interest Parity (UIP), the exchange rates will eliminate the returns received from the difference of interest rate across the respective countries. A carry trade can also be fulfilled via buying a foreign currency forward when it's at a forward discount or vice versa. The main idea is to borrow the low yielding currencies and invest in the high yielding currencies, thereby earning the spread in between. Even though theoretically we assume an arbitrage free environment, reality says otherwise

Fama (1984) confirms that regression of exchange rate changes with respect to the change in interest rate yields a value less than 1 , while it has to be equal to 1 according to UIP. That is, the returns on the high yielding currency does not equal the return on the low yielding currency taken with the expected appreciation of the foreign currency. Fama (1984) recognizes this flaw of UIP as the "forward premium puzzle". Despite the historical evidence of high returns, the carry trade positions will be exposed to higher risk as the volatility of the currency increases. The borrowers will try to close their debt positions against the respective lenders if the borrowing currencies start appreciating. Moreover, academic evidence indicates that carry trades often suffer large losses during insecure markets conditions, even though such trades perform well in conducive markets (Farhi et al. 2013, Liu et al. 2012).

In practice, developing countries account for higher interest rates on investments and therefore an attractive carry trade opportunity for the investors. On the other hand, investors are more concerned about the risk of the opportunity despite the attractiveness of the opportunity. In this context, the question arises whether the carry trade returns influence the respective crash risk. Further it is observable that most active carry traders are present in major emerging market currencies. Therefore if one currency crashes, there exists a high probability that it might spread to other surrounding economies. Despite the strength of the economy, the regulators of financial institutions are more concerned with the extreme events which might force the liquidation of the financial institution leading to an imbalance in the financial system. Therefore, this paper intends to focus this research specifically on tail risk which is frequently used by regulators in order to access the funding limits of the investors. Moreover, should the investors be concerned about the tail risk at all when they invest in high interest rate currencies?

The most trivial way to estimate tail risk is to assume that returns are normally distributed. However, due to the inefficiency of this assumption, later studies ${ }^{2}$ utilised more heavy tailed distributions such as student-t. Both these methods are most likely to either

2 Please refer to Kole and Verbeek (2006). 
underestimate or overestimate the tail risk as it does not recognise the tail of the actual distribution. Further, the financial markets have been vulnerable to extreme fluctuations in asset prices, especially during the recent global financial crisis, which gave rise to the need of effective methods that capture extreme losses. Therefore this study applies the power law distribution ${ }^{3}$ in order to estimate the thickness of the left tail of each return distribution in view of obtaining a unique estimate for each return distribution, which will allow the investment managers/risk managers to observe the possibilities of extreme losses.

This paper observes the significant effects of tail risk embedded in the carry trades of exchange rates. Findings of this research will provide evidence as to whether the regulators should account for tail risk in order to access the firm's risk on foreign currency exposure. Previous research by Menkhoff et al. (2012a) analyse the crash risk ignoring the concern of volatility clustering in financial markets. As per the findings of Mandelbort (1963), positive changes, of financial returns tend to be followed by positive changes and negative changes tend to be followed by negative changes despite the returns being large or small. In other terms, it is the serial correlation of squared returns also known as volatility clustering. The tail risk estimates of this research, capture the volatility clustering embedded in financial returns in the cause of estimating implied volatility, which is relevant in order to protect the accuracy of the tail risk estimation. In fact, this research introduces a new methodology to estimate the tail risk of financial returns.

According to the definition of UIP that the expected change in the future spot rate is directly proportional to the change in the interest rates. Therefore the excess return of the investor in a potential carry trade is the difference between the future spot rate and the forward rate for the same period. Therefore, this research examines the tail risk of a potential High-minus-Low (HML) trading strategy where, the investors will fund the high yield investment (long position) by selling a low yield investment (short position). In line with the decomposition of the carry strategy returns into interest rate returns and foreign exchange (forex) returns, this research provides evidence as to which component of this HML strategy influences more on the tail risk of a carry trade. I critically analyse the individual and collective impact of returns from long and short positions as well as forex and interest rate components, on Value-at-Risk of the respective HML strategy, the selected representation of tail risk for the purpose of this research.

This research concludes that, the proposed method of estimating the tail risk of the carry trade strategy operates effectively when currencies are relatively volatile and therefore presents a better estimate compared to pre-determined distributions (Normal and Student-t

3 The power law distribution is applied in order to identify the probability of market crashes by Embrechts et al. (1997) and Ibragimov et al. (2013). 
distributions). Further, the results suggest that, the forex component of the long position of the carry trade is the most influential in terms of the tail risk of the overall strategy.

This paper is organised as follows; Section 2 contains a summary of previous studies in this subject area. Section 3 explains the selection of data and construction of the methodology. Section 4 presents an analysis of the empirical results obtained in the research. The conclusion of this research is reported in section 5. Further, the methods applied in this research are presented in appendices.

\section{Literature Review}

Froot and Thaler (1990) explain that, there is no systematic relationship between the risk premium generated by an asset pricing model and the inconsistencies of exchange rates. Further, they claim that the bias arises only because of the expectation errors. In contrast, Bekaert (1996) claims that forward premium puzzle is explained reasonably well by the varying risk premia required to compensate for the uncertainty in the fundamentals.

Several empirical studies have explored the risks of carry trades in terms of portfolios instead of individual currencies including, Farhi and Gabaix (2013) who construct a metric called "risk reversal" (implied volatility of out-of-the-money put option minus implied volatility of out-of-the-money call option) and finds that it moves negatively with spot exchange rates. This implies when the corresponding exchange rate depreciates then the "risk reversal" increases. They further claim that, the correlation between interest rate and exchange rate depends more on net foreign trade and the vulnerability of the economy. These findings are consistent with Brunermeier et al. (2009) who claim that, inclusion of more currencies will not reduce the risk represented by skewness and kurtosis. Further, they find that, carry trades deliver negatively skewed returns and further the currency crashes increase the implied stock market volatility due to unexpected withdrawal of investments in high interest currencies. These findings were supported by Christiansen et al. (2011), who further explain that carry trade returns are related to volatility and liquidity of the equities. Extending the research of Brunermeier et al. (2009), Ferreira et al. (2013) examine the impact of funding risk on carry trade and therefore confirm that increased funding risks may contribute to high volatility of investment currency.

Menkhoff et al. (2012a) discover that high yielding currencies are exposed to global forex volatility where, low yielding currencies hedge against the volatility. They also find that liquidity risk also has a reasonable impact on currency returns. This supports the earlier findings of Burnside et al. (2011) where they state that high volatility could be related to currency crashes when there are liquidity constraints. However, Barro and Ursua (2011) claim that, even though one-third of carry trade returns are from the crash-risk premium 
during the pre-crisis analysis, carry trade return do not even compensate for the crash-risk premium when the carry trade portfolios are extended till the year 2008. Relating these findings to their paper, Farhi and Gabaix (2013), and Farhi et al. (2013) confirm that, high yielding currencies tend to depreciate in bad times while low yielding currencies tend to appreciate. Furthermore they find that the compensation requirement for crash risk after the global financial crisis is greater than it was before the crisis.

Menkhoff et al. (2012b) show that forex returns generated based on momentum strategies are not stimulated by policy regimes. However they further state that carry trade returns are mostly compensation, for the risk embedded in long positions of the trade. Lustig and Verdelhan (2007) claim that a larger portion of average exchange rate fluctuations are explained by the risk inherited in consumption growth patterns. Moreover, according to Lettau et al. (2002) the direct effects of higher interest rates on consumption are important in terms of the monetary policy of a country. These finding are consistent with Jylha et al. (2008), where they alarm the regulators as they provide evidence for carry trades to complicate the monetary policy implementation of individual countries and therefore the economies will be exposed to substantial interest and currency rate fluctuations. Therefore, the monetary aggregates of the countries in long positions of carry trades are expected to be more volatile compared to countries in short positions.

Even though there is a reasonable amount of research done on volatility as a measure of risk, research explicitly focusing on the tail risk of carry trades, is limited. Burnside et al. (2011) state that carry trade portfolio payoffs are uncorrelated with the regular risk factors. They further argue that the returns that are generated could be related to the tail risks which are mentioned as "peso events". Berge et al. (2010) provide evidence for the argument of Burnside et al. (2011), where they explain the carry trade profits perceived before the global financial crisis, merely compensate for the tail risk. Dupuy (2013) utilizes Value-at-Risk ( VaR) as the measure of risk instead of the volatility risk premia and finds that it is more effective in determining the funding limits set for the investors by the regulators. Brunermeier et al. (2009) provide evidence that highlights the importance of such limits and reasons out events leading to crash risk. They claim that when the VaR limits are violated due to the fluctuations, the regulators will be forced to close their positions. Therefore this undue selling pressure with possible overreaction may cause the carry trade currency to depreciate sharply. 


\section{Data \& Research Methodology}

\subsection{Data}

This research takes in to consideration 25 different currencies which are a mixture of developed and emerging economies that cover different regions around the world where, DataStream is the only data source. Relevant daily spot and 1 week forward rates are obtained from 29/03/2004 till 09/05/2014, keeping the U.S. Dollar (USD) as the base currency. The selected period consists of a global financial crisis, which would reflect the behaviour of each currency during such times. Moreover, Menkhoff et al. (2012a) state that, the carry trades returns decrease significantly during financial turmoil, while they are highly rewarding in a healthy financial environment. Therefore it is essential to ensure that the selected period of time includes both negative and positive market sentiments, in order to capture the respective extreme movements of carry trade returns. The currencies selected are as follows: Argentine Peso (ARS), Australian Dollar (AUD), Brazilian Real (BRL), Canadian Dollar (CAD), Chilean Peso (CLP), Chinese Yuan (CNY), Czech Koruna (CZK), Euro (EUR), Sterling Pound (GBP), Hong Kong Dollar (HKD), Hungarian Forint (HUF), New Israeli Shekel (ILS), Indian Rupee (INR), Japanese Yen (JPY), South Korean Won (KRW), Mexican Peso (MXN), New Zealand Dollar (NZD), Philippine Peso (PHP), Polish Zloty (PLN), Russian Rouble (RUB), Singapore Dollar (SGD), Thai Baht (THB), Turkish Lira (TRY), New Taiwan Dollar (TWD), South African Rand (ZAR).

\subsection{Methodology}

\subsubsection{Estimating the Tail index}

According to Mandelbort (1963), asset returns produce distributions of which the second moments are infinite, which deviate from the Gaussian distributions. He challenged the Gaussian assumptions by emphasizing the difference of financial returns distributions with the help of power laws. Supporting Mandelbort (1963), Fama (1963) finds that the empirical distribution of every stock out of thirty stocks examined, had heavier tails compared to a normal distribution. According to Embrechts et al. (1997), the returns of financial markets deviate from the Gaussian distributions and therefore there exists an excess kurtosis. Ibragimov et al. (2013), in their assessment of tail index use the power law distributions to represent the probability mass in the tails of exchange rate distributions such that,

$$
\operatorname{Pr}(|r|>x) \sim \frac{C}{x^{\zeta}}--(1)
$$


where, $r$ is the variable of interest and $\zeta$ is the tail index of the returns distribution and $\mathrm{C}$ is the normalization constant. There are mainly two methods to estimate the tail index of a returns distribution namely, log-log-rank-size method and the hills estimator (Hill 1975). However, Ibragimov et al. (2013) state the drawback of Hill's estimator such as sensitivity to dependence and small sample sizes, and hence this study uses log-log rank size to determine the tail index along with the adjustment proposed by Gabaix and Ibragimov (2011). This method is explained in Appendix A.

\subsubsection{Generating the tail risk measure}

Even though the VaR method is believed to be the most appropriate to estimate the crash risk of financial returns (Ibragimov et al. 2013, Dupuy 2013), the same method has been criticized by many researchers such as, Beder (1995), who claims that, VaR changes with the selection of the certainty. Further, VaR provides an expectation of outcomes sheltered by a specific set of assumptions, rather than the confidence of outcomes. Moreover, VaR was found non-sub additive when return distributions are extremely heavy tailed (Artzner et al. 1999). However it's discovered that sub additive property of VaR holds, whenever the tail index is greater than 1(i.e., $\zeta>1$ )(Daníelsson et al. 2013). This implies the VaR of a currency portfolio will remain lower than the aggregate risk of those currencies taken individually.

According to Table 1, it is observed that, the currencies of developed countries such as United Kingdom, Australia, Canada exhibit a higher tail index, while the currencies of emerging economies are relatively heavy tailed (lower tail index). However, none of the tail indices of selected currencies are less than 1. Therefore it is appropriate to use the VaR as our risk measure as the sub-additive property holds during the intended analysis which is very important in terms of the currency portfolios that I create later in the next section. According to Christoffersen (2012), VaR for a normal distribution is defined as follows,

$$
\operatorname{VaR}_{t+1}^{p}=\sigma_{t+1} * \phi^{-1}(P) \quad--(2)
$$

Christoffersen and Gonclaves (2004) apply GARCH(1,1) to calculate the volatility and an EVT approach to find the respective quantile in a Generalized Pareto distribution along with the Hill's estimator (Hill 1975) in order to account for volatility clustering and heavy tails in financial returns respectively. The evidence provided by Nozari et al. (2010) support the method of Christoffersen and Gonclaves (2004), where it overcame the capability of Student-t and Normal distributions. Further considering the fact that Generalized Pareto distribution is a special case of power laws and the tail index estimation is based on 
Table 1: Tail Index Estimation

\begin{tabular}{|c|c|c|c|c|}
\hline Currency & $\begin{array}{c}\text { Tail } \\
\text { Index }\end{array}$ & Constant & SE & t-Statistic \\
\hline ARS & 1.3820 & -10.4725 & 0.0087 & -159.25 \\
\hline AUD & 3.0591 & -16.6051 & 0.0104 & -293.39 \\
\hline BRL & 2.3612 & -13.1287 & 0.0096 & -246.19 \\
\hline CAD & 2.9981 & -17.2755 & 0.0156 & -192.06 \\
\hline CLP & 3.0692 & -17.3174 & 0.0286 & -107.18 \\
\hline $\mathrm{CNY}$ & 2.2545 & -18.0796 & 0.0233 & -96.68 \\
\hline $\mathrm{CZK}$ & 3.1484 & -16.9311 & 0.0166 & -189.13 \\
\hline EUR & 3.3529 & -18.4859 & 0.0209 & -160.11 \\
\hline GBP & 3.1039 & -17.6705 & 0.0172 & -180.05 \\
\hline HKD & 1.7442 & -16.7472 & 0.0091 & -191.09 \\
\hline HUF & 3.1228 & -16.3700 & 0.0159 & -196.17 \\
\hline IDR & 1.8553 & -11.6198 & 0.0149 & -124.13 \\
\hline ILS & 2.8990 & -17.2581 & 0.0292 & -99.13 \\
\hline INR & 2.2218 & -14.5987 & 0.0245 & -90.52 \\
\hline JPY & 2.8692 & -16.1926 & 0.0180 & -159.84 \\
\hline KRW & 2.1743 & -13.5067 & 0.0075 & -288.84 \\
\hline MXN & 2.5744 & -15.2736 & 0.0094 & -273.42 \\
\hline MYR & 1.9272 & -13.3888 & 0.0240 & -80.16 \\
\hline NZD & 3.2442 & -17.1961 & 0.0183 & -177.44 \\
\hline PHP & 2.6574 & -16.8542 & 0.0305 & -87.01 \\
\hline PLN & 2.9260 & -15.6626 & 0.0176 & -166.23 \\
\hline RUB & 2.1912 & -13.9642 & 0.0185 & -118.20 \\
\hline SGD & 2.7245 & -17.5486 & 0.0080 & -341.16 \\
\hline THB & 2.2314 & -14.5253 & 0.0122 & -182.24 \\
\hline TRY & 2.3992 & -13.6479 & 0.0067 & -356.76 \\
\hline TWD & 2.4656 & -16.8004 & 0.0220 & -112.13 \\
\hline ZAR & 3.0047 & -15.5601 & 0.0244 & -123.33 \\
\hline
\end{tabular}

Note: This table presents a summary of the tail index estimation by way of following the log-log-rank-size (Appendix A) method with a truncation of $10 \%$. The Tail index column is self-explanatory whereas the third column is the in tercept generated upon regression. Further SE is the standard error of the tail index followed by the corresponding t-Statistic.

power laws, it makes more sense to derive the cumulative density function (cdf), using the original probability density function (pdf) of power law distribution. Therefore, this research introduces the parameter $Z p$, which is the derived (1-p) th quantile of the power law distribution, given a probability of $\mathrm{p}$ that returns fall below the threshold. The proposed 
methodology to derive parameter $Z p$ is demonstrated in Appendix B. Christoffersen \& Gonçalves (2004) introduces a similar method to find the cdf of the distribution starting from Generalised Pareto distribution. However, this research uses the original probability density function of power laws as the starting point and derive the respective cumulative density function. Consequently, the VaR model used for this research is as follows,

$$
\operatorname{VaR}_{t+1}^{p}=\sigma_{t+1} * Z_{p}--(3)
$$

According to the equation, it is obvious that either an increase in volatility and/or a decrease in the tail index (fatter tail) will lead to higher tail risk. As per the findings of Mandelbort (1963), positive changes of financial returns tend to be followed by positive changes and negative changes tend to be followed by negative changes, despite the returns are large or small in other terms it's the serial correlation of squared returns. Bollerslev (1986) developed the Generalized Autoregressive Conditional Heteroskedasticity(GARCH) model in order to capture the serial correlation between squared returns and later $\operatorname{GARCH}(1,1)$, the simplest version of the GARCH model which was used by Orlowski (2010) in order to find the conditional volatility of exchange rates that accounts for tail risk. This research uses the following $\operatorname{GARCH}(1,1)$ model, in order to capture volatility clustering.

$$
\sigma_{t}^{2}=\omega+\alpha R_{t-1}^{2}+\beta \sigma_{t-1}^{2}--(4)
$$

In order to start the process, the unconditional expectation of $\sigma_{t}^{2}$ is considered to be $\sigma_{t}^{0}$. The parameters $\omega, \alpha, \beta$ will be estimated such that, the log Likelihood of the function is maximized. According to Hansen and Lee (1994) the Gaussian likelihood function is consistent in estimating the parameters for $\operatorname{GARCH}(1,1)$, even if the variable is non-Gaussian. Therefore the likelihood function is as follows,

$$
L_{n}(\theta)=-\frac{1}{2} \sum_{t=1}^{n}\left[\ln \left(\sigma_{t}^{2}(\theta)\right)+\frac{R_{t}^{2}}{\sigma_{t}^{2}(\theta)}\right]--(5)
$$

\subsubsection{Portfolio construction}

This research intends to create five carry trade portfolios for the selected currencies, keeping the USD as the base currency. This implies an investor in the United States, who borrows at spot rate $S_{t}$ at time $t$ and settles the loan on a date after one week. If the assumption on the expectation hypothesis holds good, then the forward rate today $F_{t}$ is 
equal to the expected spot rate after one week. Therefore I can write the excess return at time $t$ as;

$$
r_{t}=\frac{\left(S_{t+5}-F_{t, t+5}\right)}{S_{t}}--(6)
$$

This research assumes an investor who executes a carry trade each week consisting of 5 business days and he rolls over to a similar contract upon the maturity of the existing contract. Unlike most of the research available, this method provides a solution for the existence of high serial correlation that is induced by calculating daily return on a one week contract instead of using a rolling window. The following equation explains the decomposition of excess returns at time $t$ (Further explanation is given in Appendix C).

$$
\begin{gathered}
\frac{\left(S_{t+5}-F_{t, t+5}\right)}{S_{t}}=\frac{\left(S_{t+5}-S_{t+4}\right)}{S_{t}}+\frac{\left(S_{t+4}-S_{t+3}\right)}{S_{t}}+\cdots+\frac{\left(S_{t+2}-S_{t+1}\right)}{S_{t}} \\
+\frac{\left(S_{t+1}-F_{t, t+5}\right)}{S_{t}}--(7)
\end{gathered}
$$

Further decomposition of the above equation will segregate the excess returns in to two components, i.e., the forex component and the interest rate component. The detailed explanation is given in Appendix C.

Once the returns are decomposed, the research intends to find the tail risk in each components individually. Further, it is more constructive to focus our research on a particular trading strategy for a portfolio of currencies, rather than emphasizing on each currency. Therefore, this research implements a HML strategy, as it replicates the true form of a carry trade. The proposed HML strategy goes long in portfolio of high returns, while going short in portfolio of low returns. Conforming to the above argument, five portfolios are created, namely P1, P2, P3, P4 and P5, which are in ascending order according to the average returns, where $\mathrm{P} 1$ contains the currencies that produce highest average returns and currencies in P5 are the lowest of all five portfolios.

\subsubsection{Evaluating tail risk}

A recent study by Menkhoff et al. (2012a) estimate the Fama-MacBeth regression (Fama and MacBeth, 1973) which is based on the Capital Asset Pricing model (CAPM) in order to find the risk premium relevant for the excess return of a Carry trade strategy. However, the main goal of our research is to access the impact of a carry strategy return on VaR of the overall strategy, which is more inclined towards the perception of a risk manager. 
Therefore we consider $\mathrm{VaR}$ as the dependent variable of this analysis and it is regressed on returns of the overall strategy, long and short portfolio returns and, forex and interest rate components of the strategy. Autocorrelation may still exist in returns as we observe in most financial returns data. Therefore, an Ordinary Least Square (OLS) estimator can be insufficient to estimate the respective relationship between $\mathrm{VaR}$ and returns. Feasible Generalised Least Square (FGLS) estimator is considered to be the popular alternative in terms of tackling the inherent Heteroskedasticity and Autocorrelation, which makes the Gauss-Markov assumptions invalid (Hansen, 2007). However, according to Fomby et al. (2012), the FGLS may not be the most appropriate estimator, as the sample is relatively smaller and standard errors are substantially higher. Accordingly, the Heteroskedasticity and Autocorrelation Consistent (HAC) estimator introduced by Newey and West (1987), which accommodates relatively smaller samples, is used.

\section{Empirical Results}

Figure 1 represents the exchange rate return of each currency under consideration, in order to determine their nature. It is observable that, there are signs of volatility clustering in almost every currency that is under examination. Further it's evident that emerging economy currencies such as, Argentine Peso (ARS), Brazilian Real (BRL), South African Rand (ZAR), Polish Zloty (PLN) and Turkish Lira (TRY) exhibit higher levels of volatility clustering. Moreover, historical data indicates that there had been some extreme fluctuations in ARS and TRY in both positive and negative directions. However, it is seen that developed market currencies such as GBP and EUR are more volatility clustered than some of the emerging market currencies such as Chinese Yuan (CNY) and New Taiwan Dollar (TWD) as a result of pegged exchange rates in order to keep the production costs low. However, pegged exchange rates policy of a country has to be supported continuously by its reserves. There could be large depreciations if countries run out of reserves to defend the exchange rate and therefore large fluctuations (Thai Baht crisis in 1996-1997). A further look in to the tail index of each currency presented in table 1 justifies the findings of Ibragimov et al. (2013), which conclude that, the exchange rates of developing economies are heavier tailed than the developed economies and they are differently heavy-tailed among each other. However this argument may not be entirely acceptable with respect to some of the emerging market currencies. Out of the emerging economies, Chile (CLP), Hungary (HUF) and South Africa (ZAR) have a tail index, which is estimated to be $3.0692,3.1228$ and 3.0047 , respectively. This is much greater than that of developed countries such as Japan (JPY) and Canada (CAD). Further, the results indicate that, the tail index of CNY and Hong Kong Dollar (HKD) is surprisingly low despite their achievements in the past. 
Figure 1: Currency returns over time
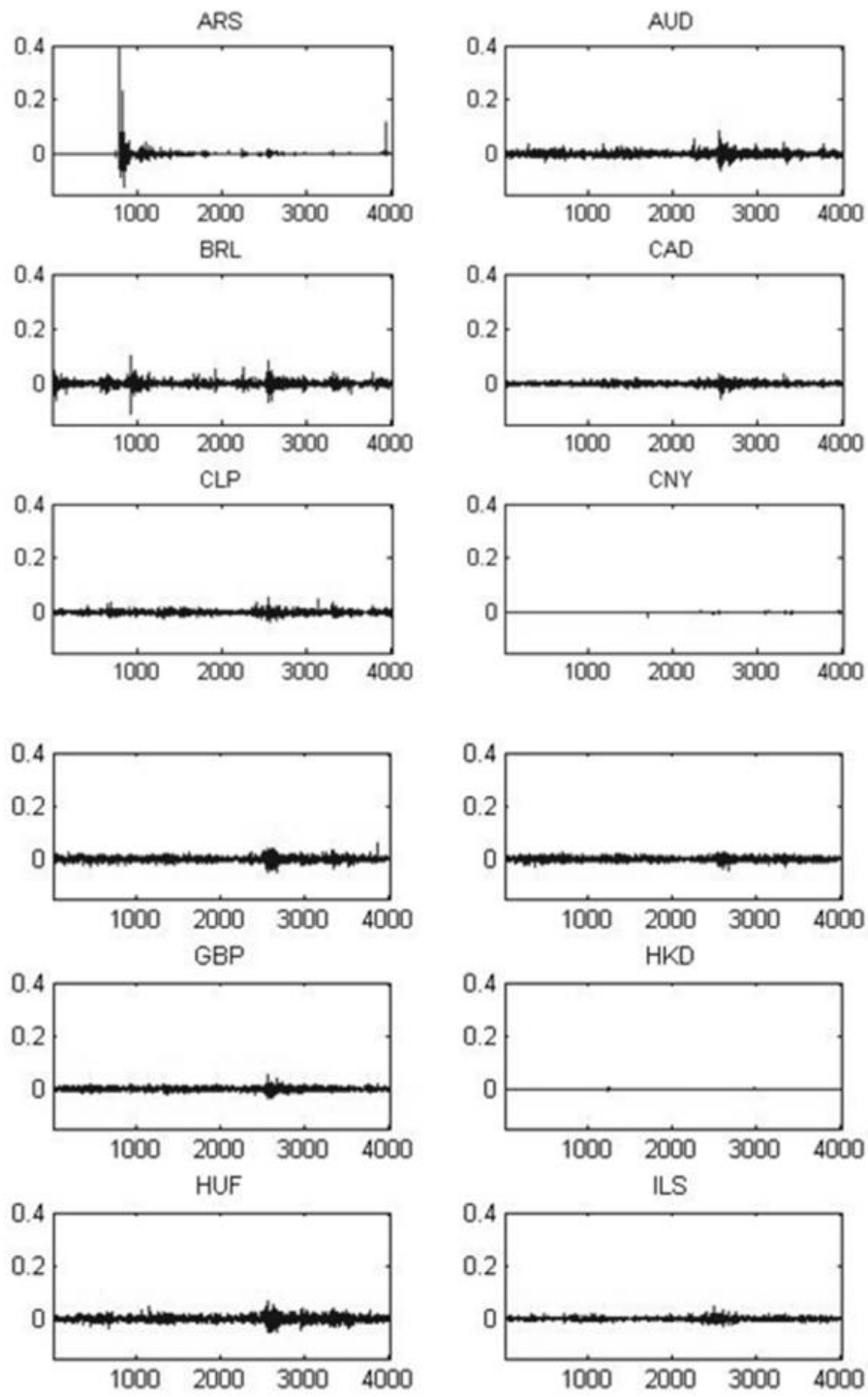

Note: The graphs exhibit the returns of all currencies across time. The vertical axis represents the daily return, while the horizontal axis represents time in days. The sample period runs from March 1998 to June 2014 where the exchange rates are from DataStream. 
Figure 1: Currency returns over time continued.
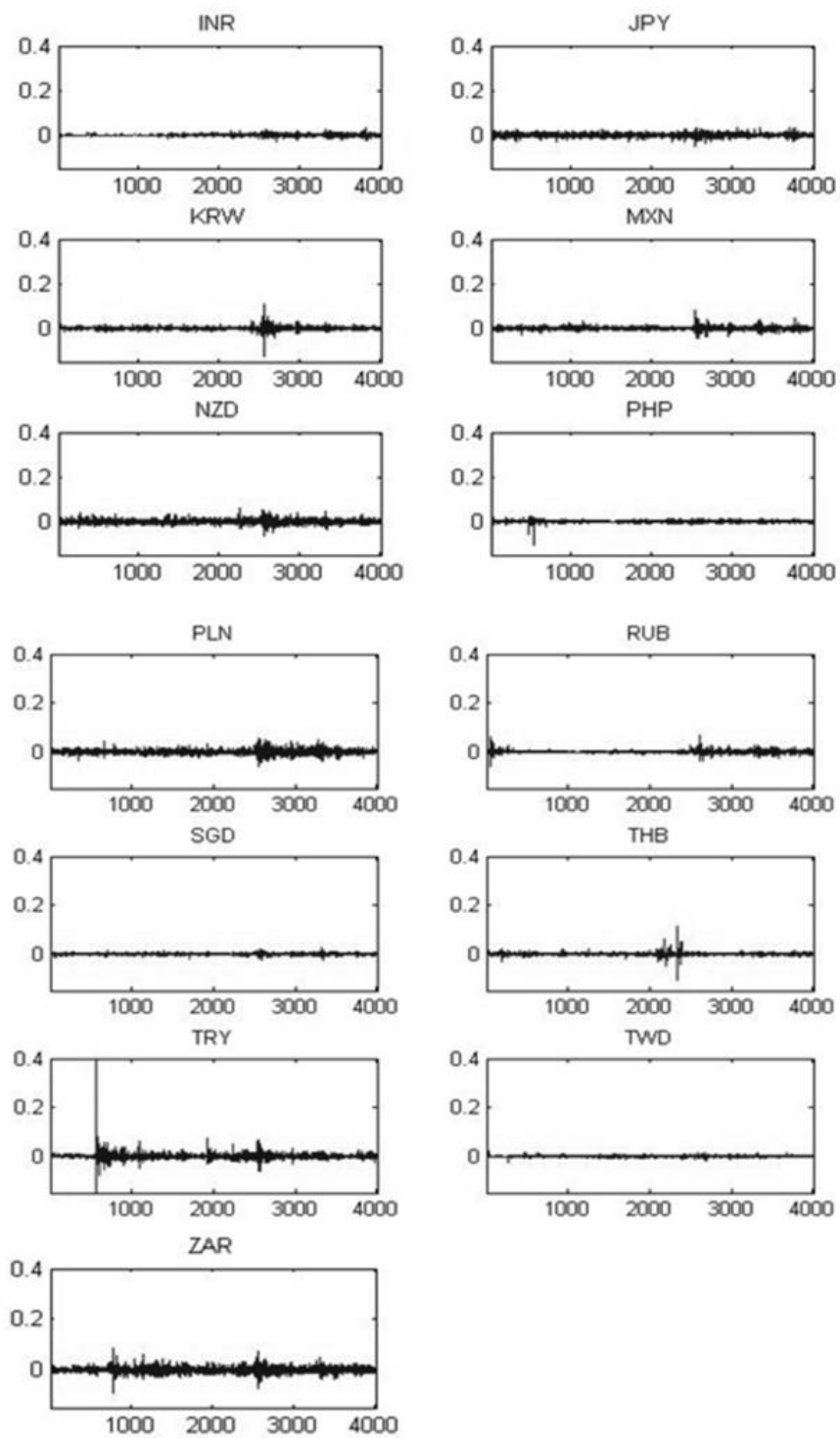

Note: The graphs exhibit the returns of all currencies across time. The vertical axis represents the daily return, while the horizontal axis represents time in days. The sample period runs from March 1998 to June 2014 where the exchange rates are from DataStream. 
Table 2 indicates the average VaR calculated using power law, Normal and Student $t$ distribution for each currency. The most significant observation is the VaR of ARS, which is estimated to be $10.92 \%$ using the Power law distribution. However the same estimation based on the assumption of either Normal or Student $t$ distributed returns, is found to be significantly low. According to the behaviour of the respective inverse function, it is sensitive to extreme historical losses and therefore ARS has a very high quantile due to its maximum historical daily loss $\left(X_{\min }\right)$ of $12.50 \%$ along with its high volatility. However despite having a low tail index, HKD appears to have a lower VaR compared to TRY which has a tail index estimated to be much higher. Further, currencies such as GBP, EUR and AUD have a higher tail index compared to CNY, their VaR is estimated to

Table 2: $\operatorname{VaR}_{1 \%}$ Estimation

\begin{tabular}{|c|c|c|c|c|c|c|}
\hline Currency & $\begin{array}{c}\text { Tail } \\
\text { Index }\end{array}$ & $\begin{array}{c}\text { Max } \\
\text { Loss/ } \\
\text { Per day } \\
\%\end{array}$ & $\begin{array}{l}\text { Average } \\
\text { Implied } \\
\text { Volatility }\end{array}$ & $\begin{array}{c}\text { VaR } \\
\text { (Power } \\
\text { Law) } \\
\%\end{array}$ & $\begin{array}{c}\mathrm{VaR} \\
\text { (Normal) } \\
\%\end{array}$ & $\begin{array}{c}\text { VaR } \\
\text { (Student-t) } \\
3 \mathrm{df} \\
\%\end{array}$ \\
\hline ARS & 1.3820 & 12.50 & 0.0131 & -10.92 & -2.02 & -2.27 \\
\hline AUD & 3.0591 & 6.05 & 0.0067 & -1.40 & -1.77 & -1.99 \\
\hline BRL & 2.3612 & 11.11 & 0.0118 & -5.49 & -2.12 & -2.39 \\
\hline CAD & 2.9981 & 5.56 & 0.0031 & -0.92 & -1.21 & -1.36 \\
\hline CLP & 3.0692 & 3.73 & 0.0042 & -0.68 & -1.40 & -1.58 \\
\hline CNY & 2.2545 & 2.01 & 0.0001 & -0.09 & -0.18 & -0.21 \\
\hline $\mathrm{CZK}$ & 3.1484 & 5.07 & 0.0060 & -1.10 & -1.73 & -1.94 \\
\hline EUR & 3.3529 & 4.16 & 0.0039 & -0.68 & -1.42 & -1.60 \\
\hline GBP & 3.1039 & 3.79 & 0.0033 & -0.62 & -1.27 & -1.43 \\
\hline HKD & 1.7442 & 0.67 & 0.0000 & -0.06 & -0.11 & -0.12 \\
\hline HUF & 3.1228 & 5.07 & 0.0083 & -1.28 & -2.00 & -2.25 \\
\hline ILS & 2.8990 & 2.83 & 0.0024 & -0.43 & -1.04 & -1.17 \\
\hline INR & 2.2218 & 3.02 & 0.0016 & -0.67 & -0.79 & -0.89 \\
\hline JPY & 2.8692 & 4.81 & 0.0043 & -1.06 & -1.50 & -1.68 \\
\hline KRW & 2.1743 & 12.42 & 0.0044 & -4.70 & -1.24 & -1.40 \\
\hline MXN & 2.5744 & 4.65 & 0.0044 & -1.17 & -1.36 & -1.53 \\
\hline NZD & 3.2442 & 6.14 & 0.0071 & -1.39 & -1.89 & -2.13 \\
\hline PHP & 2.6574 & 10.50 & 0.0018 & -1.54 & -0.85 & -0.96 \\
\hline PLN & 2.9260 & 5.89 & 0.0083 & -1.64 & -1.96 & -2.21 \\
\hline RUB & 2.1912 & 5.82 & 0.0029 & -1.67 & -0.97 & -1.09 \\
\hline SGD & 2.7245 & 2.55 & 0.0011 & -0.30 & -0.73 & -0.82 \\
\hline THB & 2.2314 & 10.45 & 0.0027 & -2.66 & -0.91 & -1.03 \\
\hline TRY & 2.3992 & 15.00 & 0.0153 & -8.93 & -2.68 & -3.01 \\
\hline TWD & 2.4656 & 2.59 & 0.0007 & -0.30 & -0.56 & -0.63 \\
\hline ZAR & 3.0047 & 9.14 & 0.0115 & -2.86 & -2.31 & -2.60 \\
\hline
\end{tabular}

Note: This table presents a summary of the $V a R$ in columns five, six and seven, with power law, normal and student-t distributions respectively. VaR is estimated at $1 \%$ probability and 3 degrees of freedom in the case of student-t distribution. Further, third and fourth column represents the Maximum \% loss per day and the average daily implied volatility. Tail index is estimated using the log-log-rank-size method demonstrated in Appendix A. 
be greater than that of CNY. This behaviour is due to the low implied volatility of the currency especially when it comes to HKD and CNY. They exhibit characteristics of a currency that has been pegged with negligible percentage of daily volatility over the years. The method that is introduced in this research provides evidence of a good VaR estimate whenever the tail index is relatively lower or when there has been an occurrence of an extreme lost in the past. Further, the VaR estimation method proves to be very sensitive when the tail index is extremely low (ex: ARG-1.382) and similarly it estimates a lower VaR compared to Normal and student-t distributions, when it comes to currencies with higher tail indices. According to Brunnermeier et al.(2009), the illiquid currencies are more vulnerable for currency crashes. Therefore a lower estimate of VaR need not be an underestimate considering the fact that some of the popular denominations such as GBP, EUR and JPY are widely held among investors and therefore more liquid relative to other currencies, which diminishes the probability of currency crashes.

Accordingly, the proposed VaR estimation methodology is proven to yield an accurate estimate in comparison with normal and student-t distributed return assumptions. Therefore the same estimation methodology will be applied to determine the VaR of the carry trade returns throughout this research.

\subsection{Impact of tail risk on the overall HML carry trade strategy}

After forming five portfolios in table 3, two HML strategies were formed, namely, P1 minus P5 (P1-P5) and P2 minus P5 (P2-P5). The former strategy produces the highest carry trade return, while the latter strategy is the best alternative in terms of returns. Returns generated were regressed on the tail risk of the HML strategy. The residuals retrieved through the OLS estimation suggest the presence of Heteroskedasticity and Autocorrelation. Which implies that the independent variable(s) and the error terms are correlated and the true variance is underestimated. Such concerns will force the rejection of the null hypothesis, even though it is true. Therefore this research uses the alternative of HAC estimator in order to estimate the regression.

According to table 4, both strategies, P1-P5 and P2-P5, obey the risk return fundamentals as the coefficients remain positive in both instances while the average return is positive. P1-P5 seems to have a better explanation for its tail risk with relatively larger adjusted $\mathrm{R}$-square compared $\left(\overline{R^{2}}\right)$ to a negligible $\overline{R^{2}}$ of P2-P5. Further, the sensitivity of returns are greater, indicating the fact that in order to realise higher gain, the investor has to account for a greater amount of risk compared to a low return carry strategy. However, the hypothesis that returns of P2-P5 strategy are not significant to explain the risk, cannot be rejected under $95 \%$ level of significance, implying that low yielding HML strategies are no longer capable of explaining the amount of risk taken. Despite its higher returns, evidence 
Table 3: Currency Portfolios

$$
r_{t}=\frac{\left(S_{t+5}-F_{t, t+5}\right)}{S_{t}} * 100 \%
$$

\begin{tabular}{cccccccccc}
\hline \multicolumn{2}{c}{ P1 } & & P2 & \multicolumn{2}{c}{ P3 } & \multicolumn{3}{c}{ P4 } & \multicolumn{3}{c}{ P5 } \\
\hline & $\begin{array}{c}r_{t} \\
(\mathbf{\%})\end{array}$ & & $\begin{array}{c}r_{t} \\
(\%)\end{array}$ & & $\begin{array}{c}r_{t} \\
(\%)\end{array}$ & & $\begin{array}{c}r_{t} \\
(\%)\end{array}$ & & $\begin{array}{c}r_{t} \\
(\%)\end{array}$ \\
\hline BRL & 11.62 & PLN & 4.633 & RUB & 3.124 & KRW & 2.079 & EUR & 0.937 \\
ARS & 5.714 & PHP & 4.517 & CLP & 2.876 & CAD & 2.013 & GBP & 0.116 \\
NZD & 5.574 & HUF & 3.963 & MXN & 2.643 & INR & 1.734 & HKD & -0.40 \\
TRY & 5.553 & THB & 3.226 & CZK & 2.581 & CNY & 1.567 & TWD & -0.99 \\
AUD & 4.860 & ILS & 3.222 & SGD & 2.131 & ZAR & 1.227 & JPY & -1.19 \\
\hline
\end{tabular}

Note: This table presents the formation of five currency portfolios P1, P2, P3, P4 and P5. These portfolios are formed according to the average returns $\left(r_{t}\right)$ generated according to the method demonstrate in Appendix C. Returns are calculated assuming a US investor entering into a one week forward currency contract. Daily returns are calculated for the period of the contract and a new contract is formed once the current contract matures. All return figures are annualised and P1 currency portfolio earns the highest return.

of high tail risk point towards P1-P5 strategy where, it produces greater excess kurtosis and negative skewness in comparison to the P2-P5 strategy. Burnside (2009) provides skewness related evidence that carry trades are exposed to crash risk where he conclude that skewness increases as the returns form long-short strategy decrease. Moreover, the results conveyed by its moments are well supported by the tail index generated through

Table 4: Return of HML strategy Vs. Currency tail risk

$$
\text { VaR }=\text { constant }+\beta\left(H M L_{\text {return }}\right)+\varepsilon-----(1)
$$

\begin{tabular}{rcccccccc}
\hline HML & $\begin{array}{c}\text { Mean } \\
\text { Return } \\
\%\end{array}$ & $\begin{array}{c}\text { Average } \\
\text { Volatility } \\
\%\end{array}$ & Kurtosis & Skew & $\begin{array}{c}\text { Tail } \\
\text { Index }\end{array}$ & Beta & t-Stat & $\begin{array}{c}\overline{R^{2}} \\
\%\end{array}$ \\
\hline P1-P5 & 6.97 & 8.6894 & 7.4417 & -0.804 & 1.6557 & 0.2960 & 2.486 & 0.96 \\
P2-P5 & 4.22 & 5.7559 & 4.7986 & -0.283 & 2.0662 & 0.0054 & 1.760 & 0.00 \\
\hline
\end{tabular}

Note: This table presents the relevant statistics and regression results of the two HML strategies, P1-P5 and P2-P5, according to the regression equation (1). The mean return and average volatility are annualised. Beta column represents the coefficient of the regression output and the next column refers to the corresponding t-statistic obtained according to Newey-west standard errors. 
power law distribution. In fact, the tail index of the overall carry trade strategy is less than most of the individual currencies indicating that it is more risky to hold the position on the carry strategy than most of the individual currencies.

These facts are well justified by the relevant histograms as presented in figures $2 \& 3$ and, it is further observed that P1-P5 strategy has a heavier left tail which implies the

Figure 2: Annualized returns of Carry trade portfolios

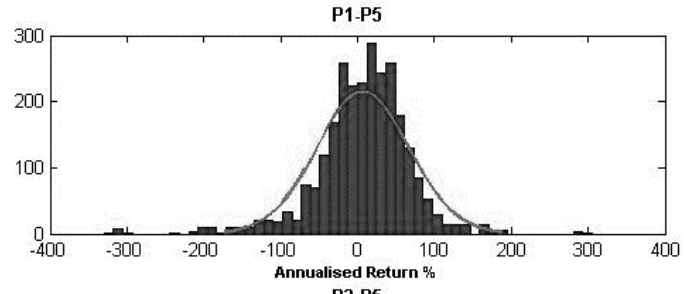

P2-P5

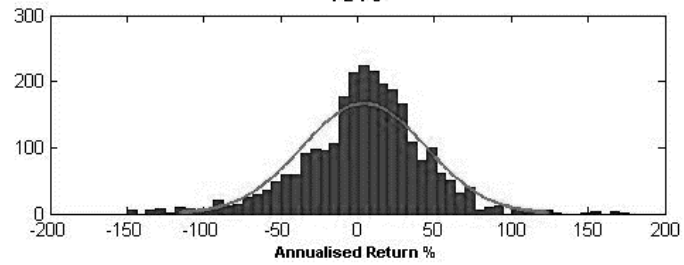

Note: The graphs exhibit the histograms for annualised returns of two carry trade strategies, P1-P5 and P2-P5. Portfolio returns of P1, P2 and P5 are calculated based on the method described in Appendix C. Both the histograms are fitted with the relevant normal distribution.

Figure 3: Annualized returns of Carry trade portfolios

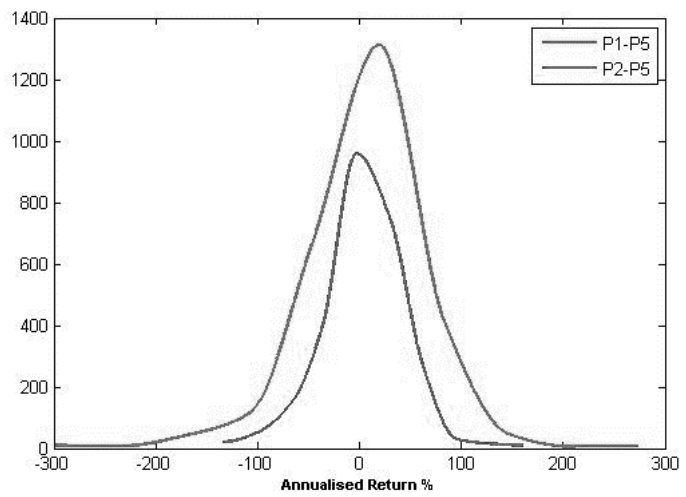

Note: The graph represents the two histograms for annualised returns of two carry trade strategies, P1-P5 and P2-P5. Marked in light is the P1-P5 strategy and P2-P5 is marked in dark. 
possibility of extreme losses than P2-P5 strategy. Therefore we can mark this difference in heavy-tailedness as a representation of the premium required to compensate for additional risk accumulated on the investment.

Graphical representation of VaR of the overall strategy across time (Figure 4) implies that $\mathrm{VaR}$ estimated explodes to higher levels once it observes high volatility in HML strategy. Such behaviour could be experienced during the time of financial turmoil in year 2008-2009 that is applicable for both the HML strategies. However, extreme movements in VaR of P2-P5 strategy appears to be lower, compared to the P1-P5 strategy conforming

Figure 4: Value-at-Risk Vs. Daily returns of carry trades
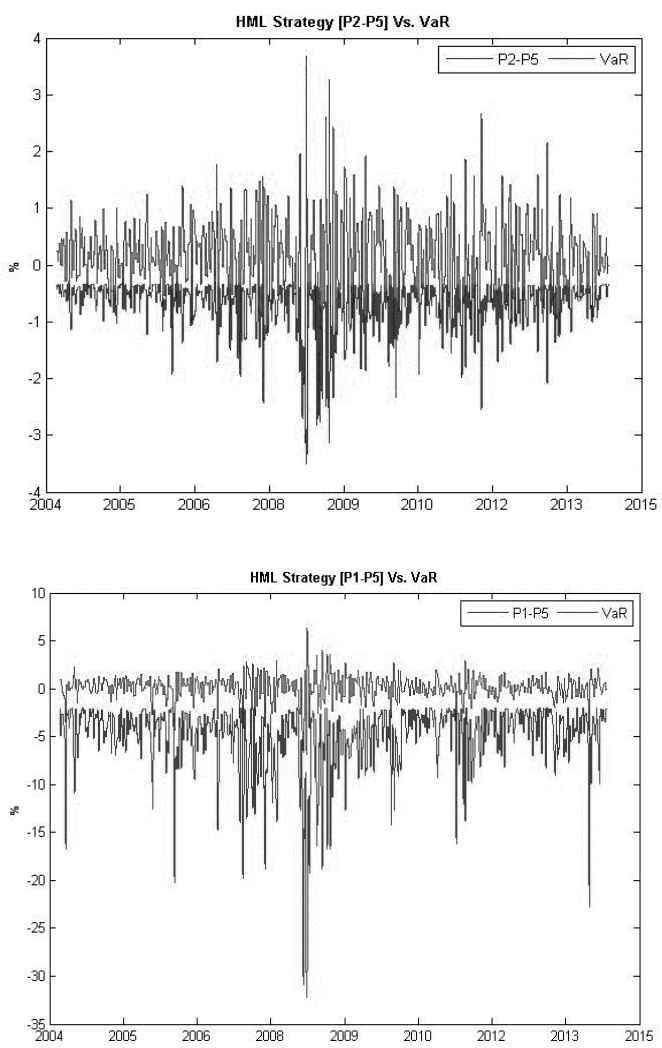

Note: The graph represents the behaviour of Value-at-Risk (VaR) (Marked in dark) along with daily returns of strategies P1-P5 and P2-P5 over time (Marked in light). Time period runs from March 2004 to June 2014. VaR is calculated using the implied volatility of the returns generated from P1-P5 strategy and inverse function estimated as demonstrated in Appendix B. 
to the difference in returns of the two strategies. A closer observation will capture the downward movement of VaR (increase in VaR) above a certain level which implies that there is a risk of holding the position tomorrow, even though both implied volatility and return today, is zero.

Therefore the proposed method of VaR estimation allows the risk management to reserve provisions in case of an unexpected market crash in the future despite today's calmness. According to Barro and Ursua (2011), the risk premium that is estimated is not sufficient to meet the crash risk after taking the period of global financial crisis in to consideration. This statement supports the results obtained with respect to the carry trade tail risk, from the fact that the explanatory power increases with the corresponding carry trade return. Therefore, more explanatory power of the regression implies better compensation for the tail risk confined. Further, it is reasonable to expect the adjusted $\overline{R^{2}}$ to increase when the effected economies are recovering from the crisis and decrease at the onset of a financial crisis. It is observed above that VaR increases exponentially when the tail index falls beyond a certain point, which implies that lower the tail index, higher the required return in order to compensate for the tail risk incurred.

\subsection{Tail risk embedded in long and short positions of HML carry trade strategy}

Having seen the impact of HML returns on the tail risk, further analysis is carried out in order to determine the influence of each long and short position of the strategy towards the overall tail risk of the strategy. The volatility of each portfolio remains uneven despite the declining returns of portfolios P1 to P5. Both kurtosis and skewness appear to follow

Table 5: The risk/return parameters of each portfolio.

\begin{tabular}{lccccc}
\hline & P1 & P2 & P3 & P4 & P5 \\
\hline Return (\%) & 6.67 & 3.91 & 2.67 & 1.72 & -0.309 \\
Volatility (\%) & 10.083 & 8.2695 & 4.6917 & 7.4058 & 2.2524 \\
Kurtosis & 8.2928 & 8.2091 & 5.5689 & 8.3134 & 3.5697 \\
Skewness & -0.8536 & -0.3591 & -0.3399 & 0.0685 & -0.0685 \\
Tail Index & 1.9332 & 2.3971 & 2.1807 & 2.3268 & 2.6251 \\
\hline
\end{tabular}

Note: This table represents the risk/return parameters of five currency portfolios, P1, P2, P3 ,P4 and P5. P1 generates the highest yield, whereas P5 generates the lowest. Return and volatility are annualised. Tail index calculated using the log-log-rank-size method, demonstrated in Appendix A. 
the returns pattern with the exception of portfolio P4. Reported results in table 4 and table 5, imply that skewness of exchange rate shock does not explain the return of each portfolio even though it explains the return of HML strategies. This contradicts with the findings of Burnside (2009) which conclude that skewness of exchange rate shocks does not explain the excess returns of HML strategy even though it explains the portfolio return. The skewness of returns is captured by the tail index estimation which considers the lowest returns of the distribution. According to the reported results, it is eminent that tail index reduces as skewness become more negative.

Table 6 indicates that if individually accounted, only the long position is significant at 95\% level of significance in terms of explaining the overall tail risk of P1-P5 strategy and none of the positions are significant in terms of P2-P5 strategy. As per the results, the returns from each long and short position, does not seem to produce a strong explanation of VaR of the overall strategy in both instances. However the explanatory power decreases with the reduction of overall returns. The long position is significant in the P1-P5 strategy where its contribution remains greater compared to the short position. Therefore the long position is the only significant component for the tail risk of the overall P1-P5 strategy. However, both long and short positions become insignificant when it comes to P2-P5 strategy, as the overall return decreases and subsequently leads to a weaker explanatory power. The results after regressing the overall $\mathrm{VaR}$ of the strategy on the individual $\mathrm{VaR}$ of each long and short portfolios (Table 7) suggest that the tail risk of the long position of the HML strategy (P1) is more capable of explaining the overall VaR. Further, the results reveal a significant relationship between the $\mathrm{VaR}$ components of each position and the VaR of the overall strategy. Both coefficients are significant at the 95 percent level of significance. However the as the return of the long position decreases, i.e., when it comes to P2-P5 strategy, the $\mathrm{VaR}$ of the long position is less significant in explaining the VaR of the overall strategy. Subsequently, the $\overline{R^{2}}$ of the respective regression drops to 66.46 percent which allows me to believe that the tail risk generated by the long side of the strategy influences more on the overall tail risk of the carry trade.

Given the compelling facts, its observable that returns of long position contributes more to the overall risk of the strategy. Literature indicates that if the central banks commit to a less active monetary policy, then it may cut down the probability of substantial fluctuations in exchange rates and therefore reduce the extreme downturns (Plantin and Shin, 2011). Moreover, Eichenbaum and Evans (1995) find that expansionary monetary policy leads to persistent depreciation of exchange rates and therefore it contributes to the volatility of exchange rates.

Steele and Wright (1996) explain that, forward premium bias is caused by rapid changes in monetary policy regimes, forcing the estimates to be incorrect. Further, the return of the long position could be written as $r t=\left(S_{t+5}-\mathrm{F}_{t, t+5}\right) / \mathrm{S}_{t}$ while the return of the 


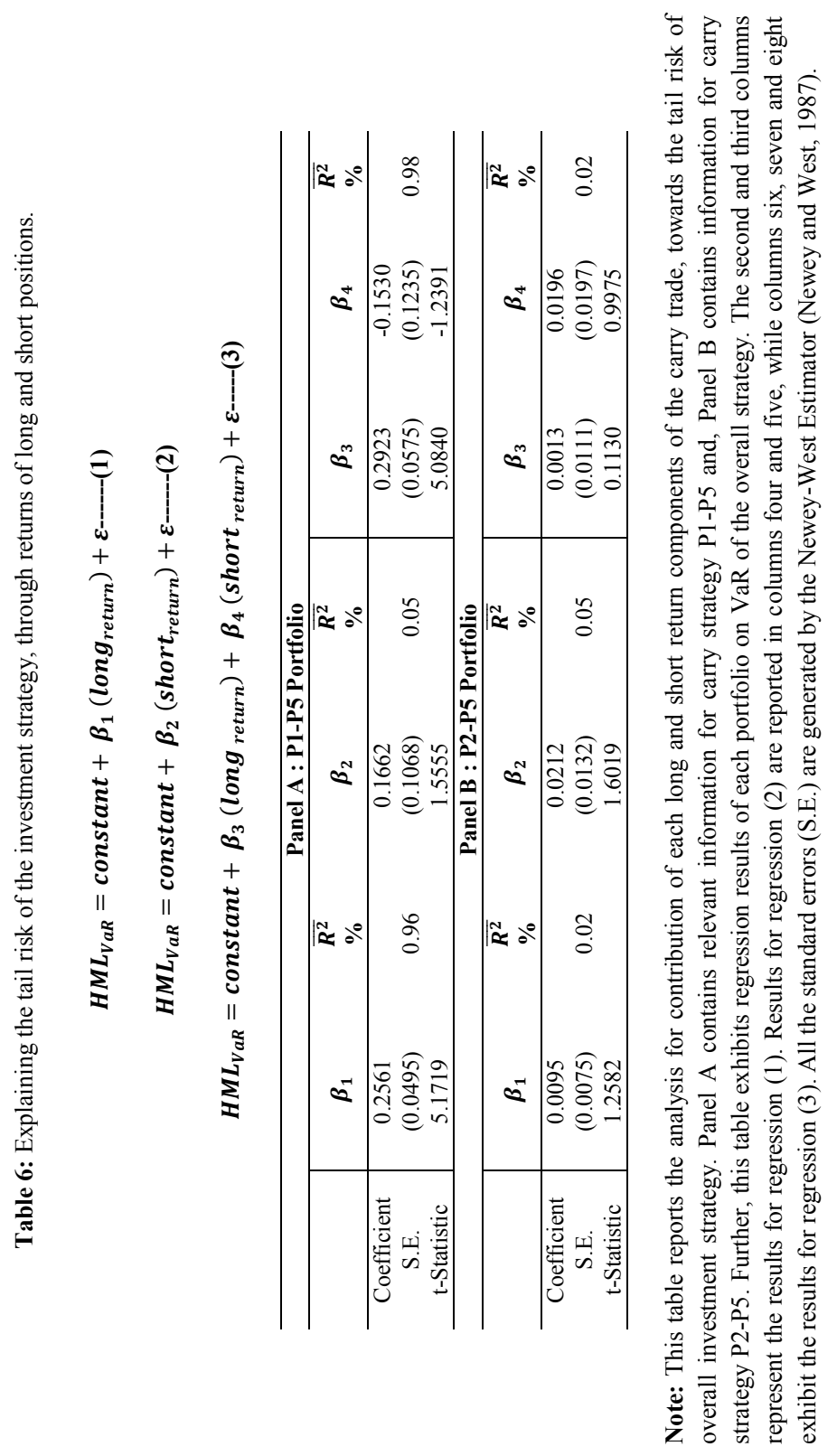




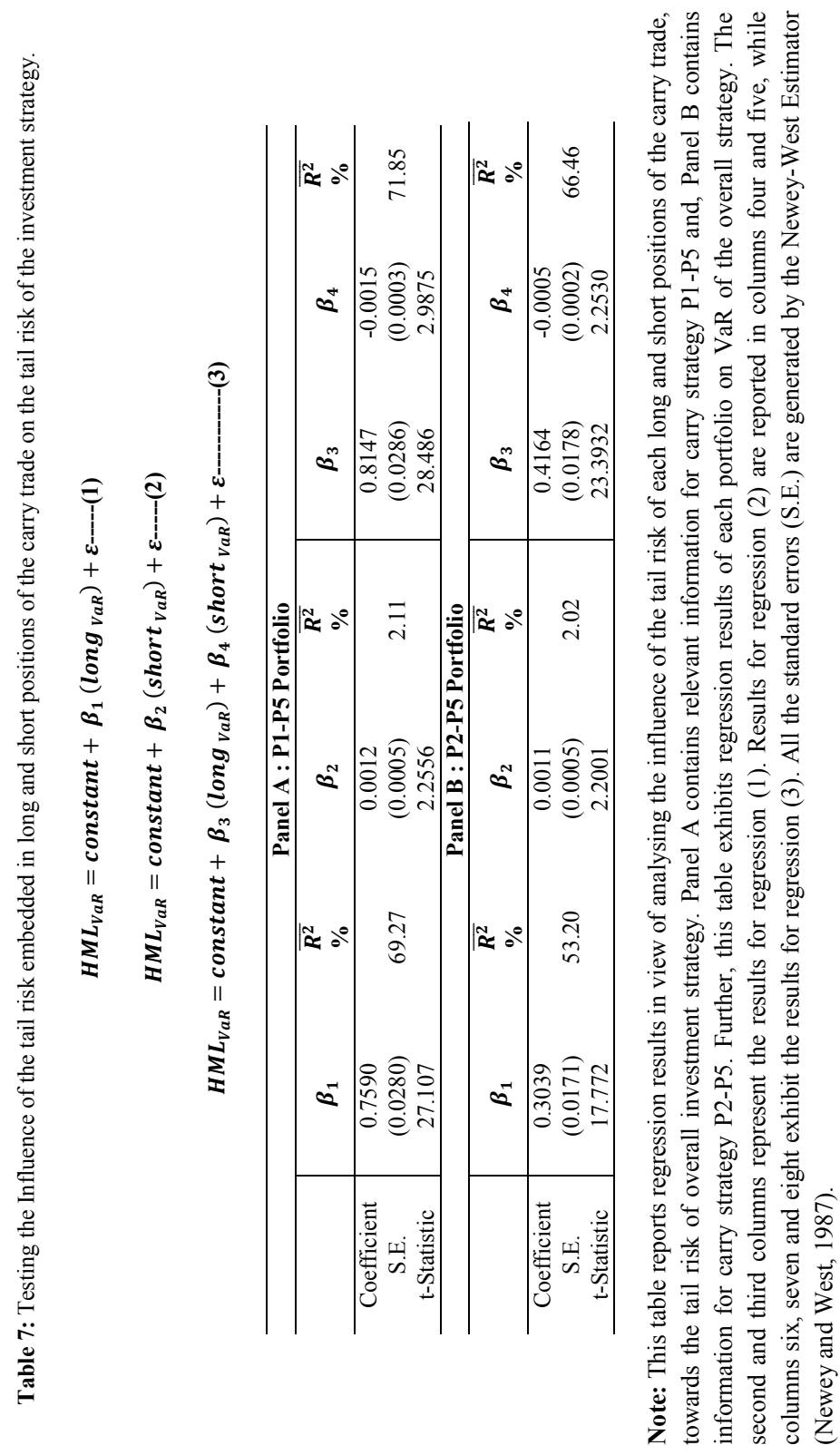


short position is $r t=-\left(S_{t+5}-\mathrm{F}_{t, t+5}\right) / \mathrm{S}_{t}$. Moreover, if the volatility of a particular exchange rate is relatively higher than others, it increases the investors' uncertainty of purchasing back the sold currency at the expected rate, at time $t+5$. Therefore the volatility of exchange rates has a positive effect on the volatility of overall returns of the respective HML strategy. Further, low volatile currencies will provide an assurance against the high volatility of the long position (Menkhoff et al. 2012a). Motivated by the strong literature stated above, the volatility of de-trended money supply (M2) is used as a measure to explain the respective causes of tail risk.

According to Table 8 , it is clearly observed that the volatility of de-trended money supply for the countries that reside in long position (P1) is substantially higher than the short position (P5). Backed by strong evidence, this implies that volatility of exchange rates of those currencies in $\mathrm{P} 1$ is much greater than that of the currencies in P2 or P5. Results indicate that, the magnitude of volatility in P1 has been hedged by the short position and consequently, the volatility of the overall strategy is less than the volatility of P1.Therefore, in the context of this research it is eminent that, long position is the greater contributor of risk to the tail risk of the overall strategy. Ferreira et al. (2013) find that, long positions of carry trades are more risky in terms of funding. When a typical carry trader prefers to exit a trade, he/she will sell the currencies in the long position and purchase the currencies in the short position. Sudden selling pressure on a relatively illiquid currency will depreciate the currency forcing the currency to crash.

Table 8: Volatility of the change in Money Supply

\begin{tabular}{c|c|c|c|c|c}
\hline \multicolumn{2}{c|}{ P1 } & \multicolumn{2}{c|}{ P2 } & \multicolumn{2}{c}{ P5 } \\
\hline Currency & $\begin{array}{c}\text { Volatility } \\
\%\end{array}$ & Currency & $\begin{array}{c}\text { Volatility } \\
\text { \% }\end{array}$ & Currency & $\begin{array}{c}\text { Volatility } \\
\%\end{array}$ \\
\hline BRL & 5.509 & PLN & 3.650 & EUR & 1.386 \\
ARS & 15.625 & PHP & 9.617 & GBP & 1.348 \\
NZD & 7.564 & HUF & 4.953 & HKD & 7.061 \\
TRY & 5.447 & THB & 3.646 & TWD & 1.862 \\
AUD & 3.009 & ILS & 3.665 & JPY & 1.509 \\
\hline Portfolio & $\mathbf{5 . 4 3 2}$ & Portfolio & $\mathbf{2 . 9 8 2}$ & Portfolio & $\mathbf{1 . 1 5 0}$ \\
\hline
\end{tabular}

Note: This table presents the annualised volatility statistics for the monthly change in money supply (M2). Assuming that there is no correlation of money supply between two countries since monetary policy of each country is independent from each other, Volatility of the portfolio could be written as,

$$
\sqrt{\sum_{i=1}^{5} w_{i}^{2} * \sigma_{i}^{2}}
$$

$w_{i}$ is the weight assigned portfolio wise, according to the USD value of money supply in each economy and $\sigma_{i}^{2}$ is the annual volatility of the change in money supply 


\subsection{Impact of returns and tail risk on Forex and interest rate return components}

The research is extended further to find the root cause of the tail risk that is inherited by each strategy, soon after exploring the impact of HML returns and long short positions, on its tail risk. Relevant information on forex and interest rate returns presented in table 9 suggests that interest rate component of the strategy generate more returns compared to the forex component. The fourth moment of returns imply that, interest rate component holds more risk compared to the forex component. However the volatility, skewness and tail risk conveys that forex component is more capable of producing extreme losses, further supported by clearly visible heavy tails in the histogram of forex returns (Figure 5). Further, there is a possibility of extreme losses to significantly reduce with the decrease in overall returns (in P2-P5 strategy). However this behaviour of the forex component is rather confusing, considering the low gain after having exposed to more extreme losses.

Table 9: The risk/return parameters of forex and interest rate return components.

\begin{tabular}{lccccc}
\hline \multicolumn{5}{c}{ Panel A : P1-P5 Portfolio } \\
\hline Portfolio & $\begin{array}{c}\text { Return } \\
\mathbf{\%}\end{array}$ & $\begin{array}{c}\text { Volatility } \\
\mathbf{\%}\end{array}$ & Kurtosis & Skew & $\begin{array}{c}\text { Tail } \\
\text { Index }\end{array}$ \\
\hline Forex & -1.2551 & 7.787 & 9.0352 & -1.518 & 1.366 \\
Interest & 8.0326 & 3.966 & 12.721 & -0.835 & 1.800 \\
\hline \multicolumn{5}{c}{ Panel B : P2-P5 Portfolio } \\
\hline \multirow{2}{*}{ Portfolio } & Return & Volatility & Kurtosis & Skew & Tail \\
& $\mathbf{\%}$ & $\mathbf{\%}$ & Index \\
\hline Forex & -0.7731 & 5.208 & 11.041 & -0.389 & 1.564 \\
Interest & 5.6296 & 2.520 & 10.388 & -0.385 & 1.915 \\
\hline
\end{tabular}

Note: This table represents the risk/return parameters of each forex and interest rate return components of the carry trade. Panel A contains relevant information for carry strategy P1-P3 and, Panel B contains information for carry strategy P2-P3. Further, this table exhibits regression results of each portfolio on $\mathrm{VaR}$ of the overall strategy. Tail index calculated using the log-log-rank-size method, demonstrated in Appendix A.

Table 10 reports the regression results of forex and interest rate return components of each portfolio on the tail risk of the respective strategy. Only the Forex return as an individual element is significant at 95 percent level of confidence, towards the explanation of the overall tail risk of the P1-P5 strategy. Neither forex nor interest rate components are significant in terms of explaining the tail risk of P2-P5. Further, the regression of the overall tail risk of the strategy P1-P5 on to forex and interest rate components strengthens the earlier result that only the forex component is significant at the 95 percent level of significance. However the explanatory powers of these regressions (i.e., Table 10 [1], [2] and [3]) are substantially weak and it further reduces with the overall return. 


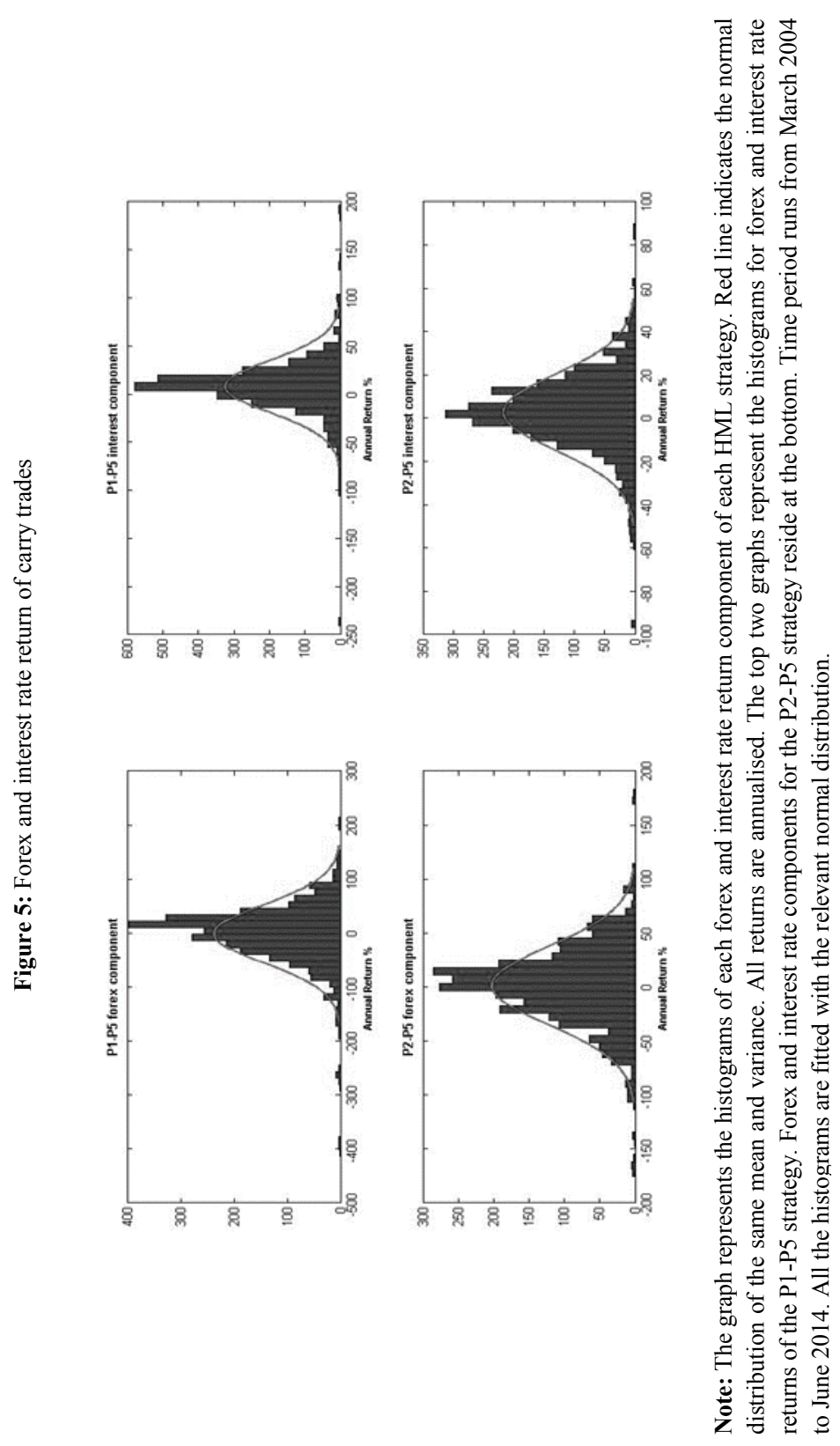




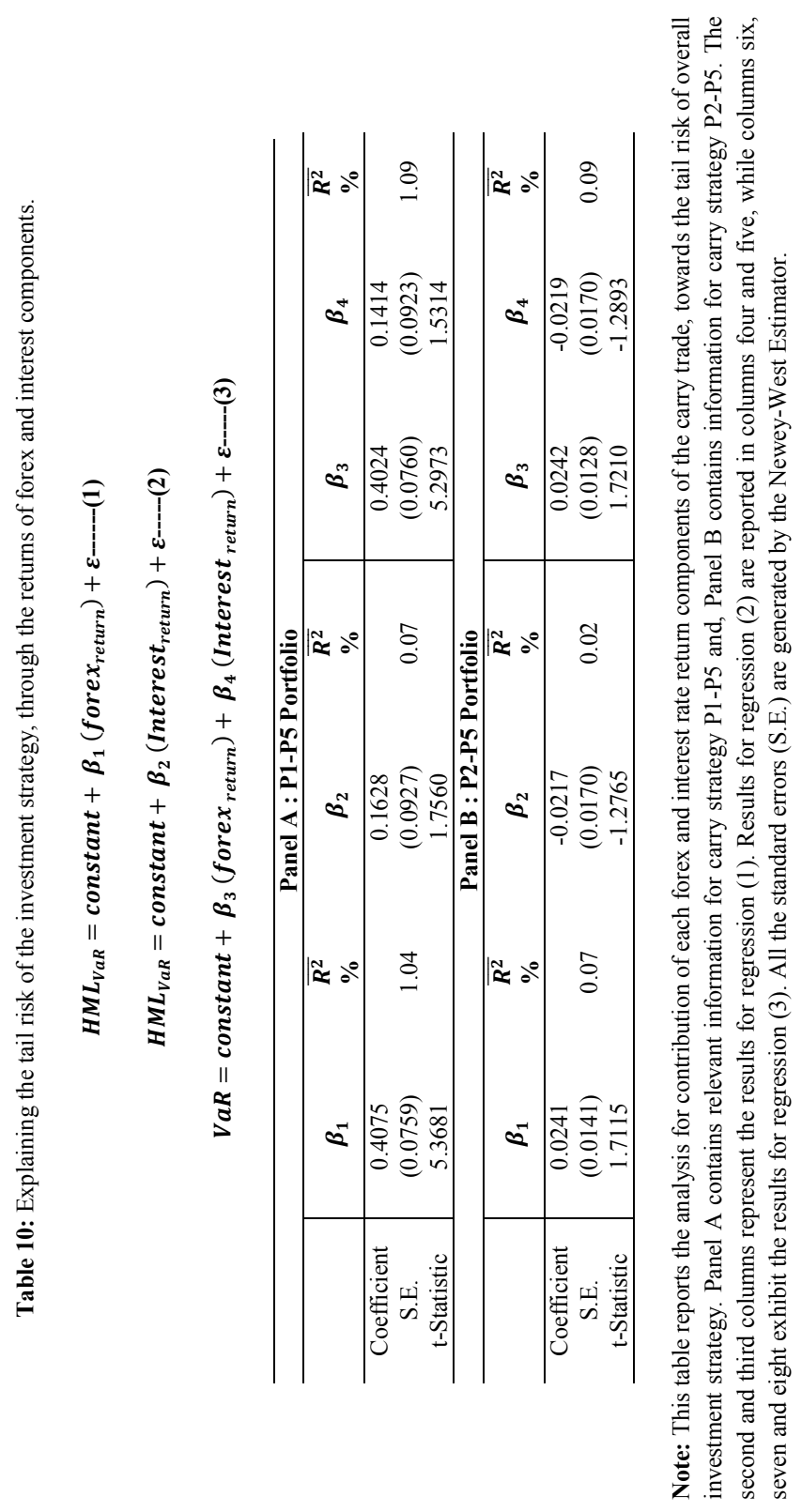




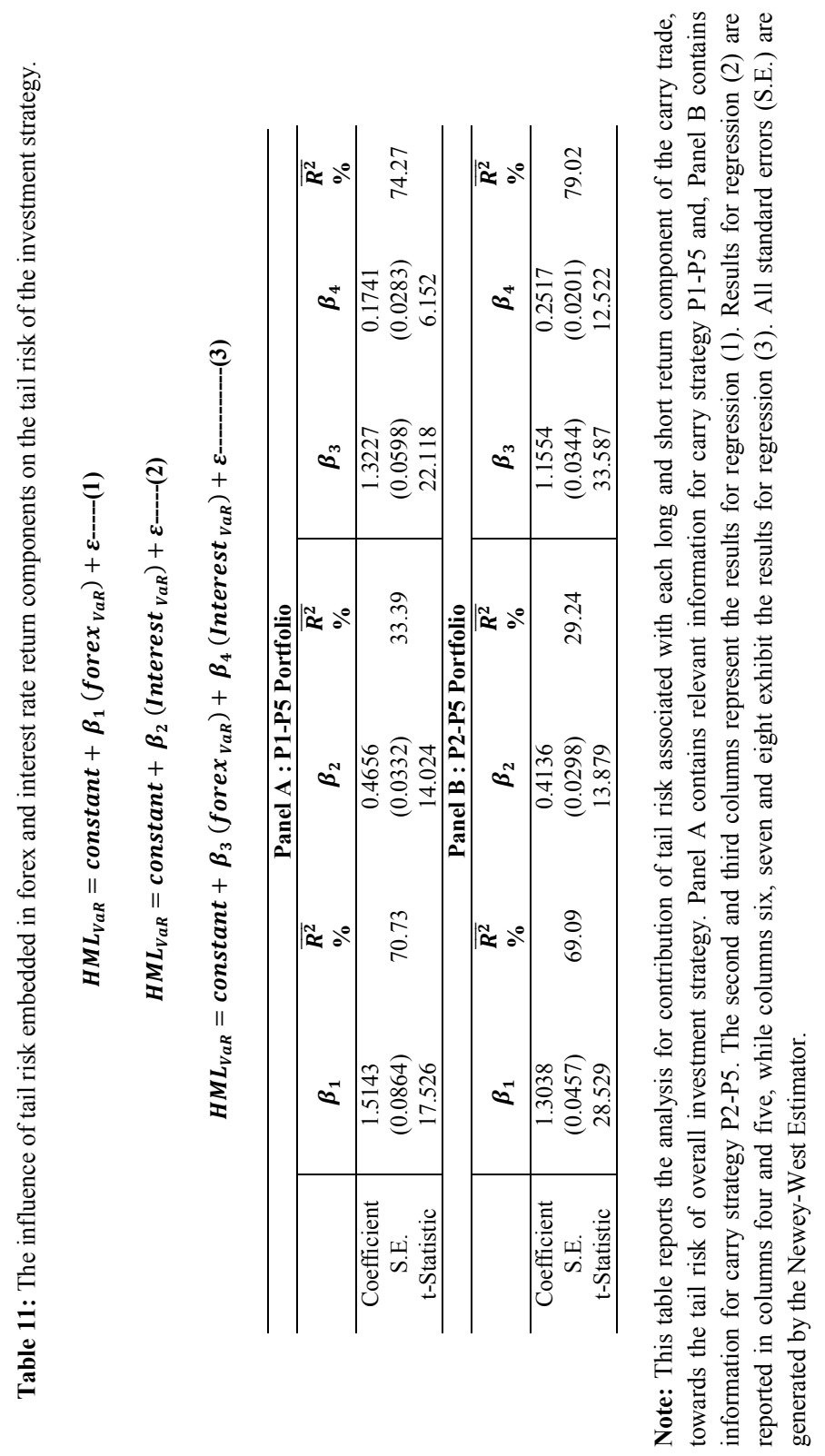


Table 11 presents the regression results of VaR of the overall strategy on the respective tail risk of forex and/or interest rate component. Even though the forex component generate a negative average return, it is significance of tail risk in explaining the tail risk of the overall strategy, P1-P5 remains greater than that of interest rate component. Moreover, the results from the regression of $\mathrm{VaR}$ of the overall strategy, collectively on forex and interest rate return (Table 11 regression [3]) agrees with its behaviour of forex and interest rate as individual components. Even though the returns of forex and interest rate returns hold a very limited explanation of overall $\mathrm{VaR}$, the VaR of forex and interest rate components suggest that, the VaR of forex return explains the overall risk more than the VaR of the respective interest rate component. Despite the consistent significance and sensitivity of the VaR of forex component, the significance and the sensitivity of the VaR of interest rate component on the overall VaR increases as the return of the overall strategy declines.

Moving forward, Arratibel and Michaelis (2014) explain that exchange rates converge to zero much faster due to a unit monetary policy shock. In contrast, the interest rate response appears to be stable across time. Earlier findings of Kearns and Manners (2006) state that the impact of monetary policy on exchange rates are almost instantaneous even though it only explains a limited portion of exchange rate volatility. Therefore, it is eminent that monetary shocks influence the exchange rates more rapidly than interest rates which increase volatility. Increased exchange rate volatility assures that the impact of exchange rates on the overall tail risk is more pronounced.

\subsection{Impact of returns and tail risk of Forex and interest rate return components belong to long and short positions}

Thus far the research examined the tail risk induced by the long/short positions and forex/ interest rate components on the HML strategy. Table 12 reports the summary results of a regression in order to analyse the collective impact of forex and interest rate return/tail risk embedded each long and short positions on the tail risk of HML strategy.

Results in Panel A indicate the null hypothesis that forex return, interest rate return of the short position and interest rate return of the long position are insignificant, cannot be rejected at $95 \%$ significance level, implying the forex return of the long position is the only significant component when it comes to explaining the VaR of HML strategy. However the explanatory power of the regression remains weak with a low $\overline{R^{2}}$ value. Panel $\mathrm{B}$ represents the results regression of the return and VaR components from P2-P5 strategy. In this case, neither the interest rate nor forex component of both long and short positions is reported to be significant at the 95 percent level of significance. Further, the regression of VaR of the HML strategy on the forex and interest rate components of both long and short positions (Table 13) are estimated, in order to find the most powerful influence on the overall tail risk. 
Table 12: Explaining the tail risk of the investment strategy, through returns of forex and interest rate components in each long and short positions.

\begin{tabular}{|c|c|c|c|c|c|}
\hline \multicolumn{6}{|c|}{ Panel A : P1-P5 Portfolio } \\
\hline & $\boldsymbol{\beta}_{1}$ & $\beta_{2}$ & $\boldsymbol{\beta}_{3}$ & $\boldsymbol{\beta}_{4}$ & $\begin{array}{l}\overline{R^{2}} \\
\%\end{array}$ \\
\hline $\begin{array}{l}\text { Coefficient } \\
\text { S.E. } \\
\text { t-Statistic }\end{array}$ & $\begin{array}{c}0.1382 \\
(0.0924) \\
1.4962 \\
\end{array}$ & $\begin{array}{c}0.3981 \\
(0.0760) \\
5.2374 \\
\end{array}$ & $\begin{array}{c}-0.0847 \\
(0.1937) \\
-0.4374 \\
\end{array}$ & $\begin{array}{c}-0.2024 \\
(0.1577) \\
-1.2831 \\
\end{array}$ & 1.10 \\
\hline \multicolumn{6}{|c|}{ Panel B : P2-P5 Portfolio } \\
\hline & $\beta_{1}$ & $\beta_{2}$ & $\boldsymbol{\beta}_{3}$ & $\beta_{4}$ & $\begin{array}{c}\overline{R^{2}} \\
\%\end{array}$ \\
\hline $\begin{array}{l}\text { Coefficient } \\
\text { S.E. } \\
\text { t-Statistic }\end{array}$ & $\begin{array}{l}-0.0241 \\
(0.0172) \\
-1.4000\end{array}$ & $\begin{array}{c}-0.0189 \\
(0.0145) \\
1.3063\end{array}$ & $\begin{array}{c}0.0343 \\
(0.0292) \\
1.1757\end{array}$ & $\begin{array}{c}0.0069 \\
(0.0250) \\
0.2781\end{array}$ & 0.11 \\
\hline
\end{tabular}

Note: This table represents the regression results in view of estimating the influence of forex and interest rate return in each long and short position of the carry trade, towards the tail risk of overall investment strategy. Panel A contains relevant information for carry strategy P1-P5 and, Panel B contains information for carry strategy P2-P5. All the standard errors (S.E.) are generated by the Newey-West Estimator.

Table 13: Explaining the tail risk of the investment strategy, through tail risk of forex and interest rate components in each long and short positions.

$$
\begin{aligned}
H M L_{V a R}=\text { constant } & +\beta_{1}\left(\text { long } I R_{V a R}\right)+\beta_{2}\left(\text { long } F X_{V a R}\right)+\beta_{3}\left(\text { Short IR } R_{V a R}\right) \\
& +\beta_{4}\left(\text { Short } F X_{V a R}\right)+\varepsilon
\end{aligned}
$$

\begin{tabular}{cccccc}
\hline \multicolumn{7}{c}{ Panel A : P1-P5 Portfolio } \\
\hline & $\boldsymbol{\beta}_{\mathbf{1}}$ & $\boldsymbol{\beta}_{\mathbf{2}}$ & $\boldsymbol{\beta}_{\mathbf{3}}$ & $\boldsymbol{\beta}_{\mathbf{4}}$ & $\begin{array}{c}\overline{\boldsymbol{R}^{\mathbf{2}}} \\
\mathbf{0}\end{array}$ \\
\hline Coefficient & 0.1546 & 1.0893 & -1.7225 & -4.0649 & 56.38 \\
S.E. & $(0.0346)$ & $(0.0784)$ & $(0.9575)$ & $(1.2436)$ & \\
t-Statistic & 4.4682 & 13.894 & 1.7989 & 3.2686 & \\
\hline \multicolumn{7}{c}{ Panel B : P2-P5 Portfolio } \\
\hline Coefficient & 0.1514 & $\boldsymbol{\beta}_{\mathbf{2}}$ & $\boldsymbol{\beta}_{\mathbf{3}}$ & $\boldsymbol{\beta}_{\mathbf{4}}$ & $\overline{\boldsymbol{R}}$ \\
S.E. & $(0.0202)$ & $(0.0375)$ & -0.9322 & -1.0030 & \\
t-Statistic & 7.4950 & 15.248 & $0.1346)$ & $(0.1558)$ & 49.47 \\
\hline
\end{tabular}

Note: This table represents the Newey-West regression results of the tail risk associated with each forex and interest rate return component present in each long and short position of the carry trade, and its influence on the tail risk of overall investment strategy. Panel A contains relevant information for carry strategy P1-P5 and, Panel B contains information for carry strategy P2-P5. All the standard errors (S.E.) are generated by the Newey-West Estimator. 
The results on each panel A and B suggest the null hypothesis that the coefficients of forex return, interest rate return of the long position and interest rate return of the short position are statistically insignificant at the 95 percent significance level. Other than the interest rate component of the short position, the significance of all coefficients increase with the decrease in returns. However the explanatory power decreases with the overall return of the strategy. The results given above (Table 12 and 13) demonstrate that, out of the four return components mentioned, the forex return of the long position is the only component capable of explaining the tail risk of the strategy.

Furthermore, the tail risk of the forex component that is embedded in the long position is reported to be the most significant component that affects the overall tail risk of the strategy. Therefore, the forex component of the long position is undoubtedly the most influential component on the overall tail risk at 95 percent significance.

The previous sections explain the impact of money supply on the volatility of the exchange rates and its speed of impact on exchange rate as well as interest rates, which lead to the conclusion that the tail risk of HML strategy is substantially influenced by the long position and the forex component of carry trade return. Therefore as a corollary, this research reports that the tail risk of carry trades is most influenced by the forex component of the long position.

\section{Conclusion}

This research was designed to analyse the origin of the tail risk of a potential HML strategy which is a popular investment style in the context of forex. Existing studies in this field of research have proven the existence of a crash risk premium that explains the expected returns. However the research focuses on tail risk exposure of an investor as a result of carry trades in order to provide the risk managers and regulators with a critical explanation of where things can go wrong. Consequently, this research applies the concepts of extreme value theory in order to estimate the tail risk induced as a result of a potential carry trade opportunity.

A new method was proposed in view of estimating the cumulative distribution function of the left tail of the returns distribution with the application of purely based on power law distribution. Further, the measure for tail risk is established using the implied volatility of returns estimated through GARCH $(1,1)$ model and the corresponding cumulative distribution function of the returns distribution. This measure produces a better estimate of tail risk especially in the case of heavy left tails where normal and student-t distributions cannot reach. Further, a better estimate of tail risk is observed even when the currency returns are not heavy tailed, since this method captures the actual shape of each return 
distribution. Having observed its effectiveness, this research utilizes the same method in order to estimate the VaR of a potential carry trade.

The research finds that, the returns of the HML strategy bears a weak explanatory power over the VaR of its returns and it diminished with the overall return. When the returns are low under low volatility conditions, the VaR of the strategy converges close to a minimal level. Moreover, when there are signs of a crisis such as, patches of volatility clusters and high volatility climate, the VaR estimation models behave more responsively.

Further the analysis indicates that the skewness and the tail index explain the risk return relationship of the HML strategy even though it may not be the case in the context of portfolios as well as forex and interest rate components of the HML strategy. Regression results and existing literature suggest that long position of the trade explains the VaR of the overall strategy better than the short position and moreover, the forex component dominates over the interest rate component in terms of explaining the overall tail risk. Therefore this research concludes that, the forex return of the long position of the trade is the most influential component that is responsible for the tail risk of the overall strategy. However, results show that carry trade returns have a weaker explanatory power on the respective tail risk. According to the findings of this research, countries with high volatility of monetary aggregates are incorporated with a higher tail risk. Therefore, the tail risk increases with the activities leading to such variations in the domestic monetary aggregates. These situations may occur either due to a sudden withdrawal or an injection of money by an external party, such as a foreign investor or because of an internal policy decision made by the Central bank.

This research follows the method by Ibragimov et al. (2013), which truncates the dataset by 10 percent, in order to eliminate the most extreme values that would hinder the estimation of tail index. However, this method could be further extended with truncation independent VaR estimation methods, so that the entire range of observations could be utilized to determine the heavy-tailedness of the returns distribution. 


\section{References}

Arratibel, O. \& Michaelis, H. 2014, "The impact of monetary policy and exchange rate shocks in Poland: evidence from a time-varying VAR", European Central Bank: Working paper series, Vol. No. 1636, February.

Artzner, P., Delbaen, F., Eber, J. \& Heath, D. 1999, "Coherent measures of risk", Mathematical finance, Vol. 9, No. 3, pp. 203-228.

Barro, R.J. \& Ursúa, J.F. 2011, “Rare macroeconomic disasters", Working papers: Harvard Business School.

Beder, T.S. 1995, "VaR: Seductive but dangerous", Financial Analysts Journal, pp. 12-24.

Bekaert, G. 1996, "The time variation of risk and return in foreign exchange markets: A general equilibrium perspective", Review of Financial Studies, Vol. 9, No. 2, pp. 427470 .

Berge, T., Jorda, O. \& Taylor, A. M. 2010, “Currency carry trades”, University of California.

Bollerslev, T. 1986, "Generalized autoregressive conditional heteroskedasticity", Journal of Econometrics, Vol. 31, No. 3, pp. 307-327.

Brunnermeier, M. K., Nagel, S. \& Pedersen, L. H. 2009, "Carry trades and currency crashes", Vol. 23, pp. 313-347, NBER Macroeconomics Annual, Vol. 23, pp. 313-347.

Burnside, C. 2009, "Comment on carry trades and currency crashes" in NBER Macroeconomics Annual 2008, Vol. 23 University of Chicago Press, pp. 349-359.

Burnside, C., Eichenbaum, M., Kleshchelski, I. \& Rebelo, S. 2011, "Do peso problems explain the returns to the carry trade?", Review of Financial Studies, Vol. 24, No. 3, pp. 853-891.

Christiansen, C., Ranaldo, A. \& and Soderlind, P. 2011, "The time-varying systematic risk of carry trade strategies", Journal of Financial and Quantitative Analysis, Vol. 46, pp. 1107-1125.

Christoffersen, P. \& Gonçalves, S. 2004, Estimation risk in financial risk management, CIRANO.

Christoffersen, P. F. 2012, Elements of financial risk management, 2nd ed. edn, Academic, Oxford. 
Daníelsson, J., Jorgensen, B.N., Samorodnitsky, G., Sarma, M. \& de Vries, C.G. 2013, "Fat tails, VaR and subadditivity", Journal of Econometrics, Vol. 172, No. 2, pp. 283-291.

Dupuy, P. 2013, “The tailed risk premia of the carry trades”, Grenoble Ecole de Management.

Eichenbaum, M. \& Evans, C. L. 1995, "Some empirical evidence on the effects of monetary policy shocks on exchange rates", Quarterly Journal of Economics, p. 1975.

Embrechts, P., Klüppelberg, C. \& Mikosch, T. 1997, Modelling extremal events: for insurance and finance, Springer.

Fama, E. F. \& MacBeth, J. D. 1973, "Risk, return, and equilibrium: Empirical tests", The Journal of Political Economy, pp. 607-636.

Fama, E. F. 1963, "Mandelbrot and the Stable Paretian Hypothesis", The Journal of Business, Vol. 36, No. 4, pp. 420-429.

Farhi, E., Fraiberger, S.P., Gabaix, X., Ranciere, R. \& Verdelhan, A. 2013, Crash risk in currency markets, National Bureau of Economic Research.

Farhi, E. \& Gabaix, X. 2013, "Rare disasters and exchange rates", NBER Working Paper, Vol. No. 13805.

Ferreira Filipe, S. \& Suominen, M. 2013, "Currency carry trades and funding risk", AFA 2014 Philadelphia Meetings.

Fomby, T.B., Hill, R.C. \& Johnson, S.R. 2012, Advanced econometric methods, Springer Science \& Business Media.

Froot, K.A. \& Thaler, R.H. 1990, “Anomalies: foreign exchange”, The Journal of Economic Perspectives, pp. 179-192.

Gabaix, X. \& Ibragimov, R. 2011, "Rank-1/2 : a simple way to improve the OLS estimation of tail exponents", Journal of Business \& Economic Statistics, Vol. 29, No. 1, pp. 24-39.

Hansen, C.B. 2007, "Generalized least squares inference in panel and multilevel models with serial correlation and fixed effects", Journal of Econometrics, Vol. 140, No. 2, pp. 670-694.

Hill, B. M. 1975, “A simple general approach to inference about the tail of a distribution”, The annals of statistics, Vol. 3, No. 5, pp. 1163-1174.

Ibragimov, M., Ibragimov, R. \& Kattuman, P. 2013, "Emerging markets and heavy tails", Journal Of Banking \& Finance, Vol. 37, No. 7, pp. 2546-2559. 
Jylhä, P., Lyytinen, J. \& Suominen, M. 2008, “Arbitrage capital and currency carry trade returns", AFA 2009 San Francisco Meetings Paper.

Kearns, J. \& Manners, P. 2006, "The impact of monetary policy on the exchange rate: A study using intraday data", International Journal of Central Banking, Vol. 2, No. 4, pp. 157-183.

Lee, S. \& Hansen, B. E. 1994, "Asymptotic theory for the GARCH $(1,1)$ quasi-maximum likelihood estimator", Econometric theory, Vol. 10, No. 01, pp. 29-52.

Lettau, M., Ludvigson, S. \& Steindel, C. 2002, "Monetary policy transmission through the consumption-wealth channel", Economic Policy Review, Federal Reserve Bank of New York.

Lustig, H. \& Verdelhan, A. 2007, "The cross section of foreign currency risk premia and consumption growth risk", American Economic Review, Vol. 97, No. 1, pp. 89-117.

Mandelbort, B. 1963, "The variation of certain speculative prices", The Journal of Business, Vol. 36, No. 4, pp. 394-414.

Menkhoff, L., Sarno, L., Schmeling, M. \& Schrimpf, A. 2012a, "Carry trades and global foreign exchange volatility”, Journal of Finance, Vol. 67, No. 2, pp. 681-718.

Menkhoff, L., Sarno, L., Schmeling, M. \& Schrimpf, A. 2012b, "Currency momentum strategies”, Journal of Financial Economics, Vol. 106, No. 3, pp. 660-684.

Newey, W. K. \& West, K. D. 1987, “A simple, positive semi-definite, heteroskedasticity and autocorrelation consistent covariance matrix", Econometrica, Vol. 55, No. 3, pp. 703-708.

Nozari, M., Raei, S. M., Jahangiri, P. \& Bahramgiri, M. 2010, “A comparison of heavytailed VaR estimates and filtered historical simulation: Evidence from emerging markets", International Review of Business Research Papers, Vol. 6, No. 4, pp. 347-359.

Orlowski, L. 2010, "Proliferation of tail risks and policy responses in the EU financial markets", European Economy.

Plantin, G. \& Shin, H. S. 2011, Carry trades, monetary policy and speculative dynamics, Centre for Economic Policy Research.

Steele, D. \& Write, J. (1996) The forward premium bias under different monetary policy environments, Department of Economics, University of New Zealand. 


\section{Appendix A}

According to power law, we have,

$$
\begin{gathered}
\operatorname{Pr}(X>x) \approx \frac{C}{x^{\zeta}} \\
\log \operatorname{Pr}(X>x) \approx c-\zeta \log (x)
\end{gathered}
$$

Since we are interested in the left tail of the distribution, order the observations such that

$$
X_{1} \leq X_{2} \leq X_{3} \ldots \ldots \leq X_{n} \ldots \ldots \ldots \ldots \ldots \leq X_{N}
$$

This research uses the truncation value 10 percent such that, $n=N * 10 \%$

Taking $\quad X_{k} \quad$ we have

$$
\operatorname{Pr}(X>x)=\operatorname{Pr}\left(X>X_{k}\right) \approx \frac{k}{N}=\text { Rank }
$$

Therefore we have the log-log rank-size regression as

$$
\log (\operatorname{Rank}) \approx c-\zeta \log \left(X_{k}\right)
$$

Further I employ the constant $\gamma=0.5$ introduced in to the above regression by (Gabaix, Ibragimov 2011) in order to make the analysis more robust.

$$
\log (\operatorname{Rank}-\gamma) \approx c-\zeta \log \left(X_{k}\right)
$$




\section{Appendix B}

According to power laws, the Probability Density Function (pdf) is $p(x)$,

$$
p(x)=\frac{\zeta-1}{X_{\min }}\left(\frac{x}{X_{\min }}\right)^{-\zeta}
$$

Where, $X_{\min }$ is the minimum value of returns and $\zeta$ is the tail index of the distribution as calculated in Appendix A. In the scenario of tail risk, it's essential to focus this research on the left tail of the power law distribution. Therefore, in order to determine the Cumulative Density Function (cdf), the pdf will be integrated w.r.t. $\mathrm{x}$ between $X_{\min }$ and $x$.

$$
\mathrm{P}(\mathrm{X})=\operatorname{Pr}(\mathrm{X}<=\mathrm{x})=\int_{X_{\min }}^{x} \frac{\zeta-1}{X_{\min }}\left(\frac{X}{X_{\min }}\right)^{-\zeta} d x
$$

Since $X_{\min }$ and $\zeta$ are constants,

$$
\operatorname{Pr}(\mathrm{X}<=\mathrm{x})=\frac{\zeta-1}{X_{\min }{ }^{-\zeta+1}} \int_{X_{\min }}^{x}(X)^{-\zeta} d x
$$

After integrating and applying limits; 


$$
\operatorname{Pr}(\mathrm{X}<=\mathrm{x})=1-\left(\frac{X_{\min }}{x}\right)^{\zeta-1}
$$

If $\mathrm{p}$ is the probability that returns fall below the threshold then the (1p)th quantile of the power law distribution $Z_{p}$ is

$$
Z_{p}=\frac{X_{\min }}{\sqrt[\zeta-1]{p}}
$$

Further, $\mathrm{p}$ is the conditional probability that $x \geq X_{\min }$ and therefore,

$$
\begin{gathered}
p=\operatorname{Pr}\left(\mathrm{x} \geq \operatorname{VaR}_{a \%} \mid \mathrm{x} \geq X_{\text {min }}\right)=\frac{\operatorname{Pr}\left(\mathrm{x} \geq \operatorname{VaR}_{a \%} \cap \mathrm{x} \geq X_{\text {min }}\right)}{\operatorname{Pr}\left(x \geq X_{\text {min }}\right)} \\
=\frac{\operatorname{Pr}\left(\mathrm{x} \geq \operatorname{VaR}_{a \%}\right)}{\operatorname{Pr}\left(x \geq X_{\text {min }}\right)}=\frac{a \%}{\text { Truncation } \%}
\end{gathered}
$$




\section{Appendix C}

\section{Estimating daily returns earned through a one week carry trade}

I write the carry trade return for a period one week as,

$$
R_{t}=\left(S_{t+5}-F_{t, t+5}\right) / S_{t}
$$

Decomposing the original formula gain at time $t$ will be

$$
\begin{aligned}
\frac{\left(S_{t+5}-F_{t, t+5}\right)}{S_{t}}= & \frac{\left(S_{t+5}-S_{t+4}\right)}{S_{t}}+\frac{\left(S_{t+4}-S_{t+3}\right)}{S_{t}}+\cdots+\frac{\left(S_{t+1}-S_{t}\right)}{S_{t}} \\
& +\frac{\left(S_{t}-F_{t, t+5}\right)}{S_{t}}
\end{aligned}
$$

Further, gain of the carry trade at time $\mathrm{t}+1$ will be

$$
\begin{aligned}
\frac{\left(S_{t+5}-F_{t, t+5}\right)}{S_{t+1}}= & \frac{\left(S_{t+5}-S_{t+4}\right)}{S_{t+1}}+\frac{\left(S_{t+4}-S_{t+3}\right)}{S_{t+1}}+\cdots \\
& +\frac{\left(S_{t+2}-S_{t+1}\right)}{S_{t+1}}+\frac{\left(S_{t+1}-F_{t, t+5}\right)}{S_{t+1}}
\end{aligned}
$$


Estimating daily forex and interest rate returns earned through a one week carry trade

I reconsider the initial decomposition to estimate the carry trade return at time $\mathrm{t}$

$$
\begin{aligned}
\frac{\left(S_{t+5}-F_{t, t+5}\right)}{S_{t}}= & \frac{\left(S_{t+5}-S_{t+4}\right)}{S_{t}}+\frac{\left(S_{t+4}-S_{t+3}\right)}{S_{t}}+\cdots+\frac{\left(S_{t+1}-S_{t}\right)}{S_{t}} \\
& +\frac{\left(S_{t}-F_{t, t+5}\right)}{S_{t}}
\end{aligned}
$$

After combining all terms except the last term, I get;

$$
\frac{\left(S_{t+5}-F_{t, t+5}\right)}{S_{t}}=\underbrace{\frac{\left(S_{t+5}-S_{t}\right)}{S_{t}}}_{\text {Forex return }}+\underbrace{\frac{\left(S_{t}-F_{t, t+5}\right)}{s_{t}}}_{\begin{array}{c}
\text { Interest } \\
\text { rate return }
\end{array}}
$$

